OPEN ACCESS

Approved by:

Frontiers Editorial Office,

Frontiers Media SA, Switzerland

${ }^{*}$ Correspondence:

Tal Shafir

gah/@umich.edu

Specialty section:

This article was submitted to Psychology for Clinical Settings,

a section of the journal

Frontiers in Psychology

Received: 25 January 2020 Accepted: 27 January 2020 Published: 18 February 2020

Citation:

Melzer A, Shafir T and Tsachor RP

(2020) Corrigendum: How Do We Recognize Emotion From Movement?

Specific Motor Components

Contribute to the Recognition of Each Emotion. Front. Psychol. 11:184

doi: 10.3389/fpsyg.2020.00184

\section{Corrigendum: How Do We Recognize Emotion From Movement? Specific Motor Components Contribute to the Recognition of Each Emotion}

\author{
Ayelet Melzer ${ }^{1}$, Tal Shafir ${ }^{2 *}$ and Rachelle Palnick Tsachor ${ }^{3}$ \\ ${ }^{1}$ Faculty of Social Welfare and Health Sciences, The Graduate School of Creative Arts Therapies, University of Haifa, Haifa, \\ Israel, ${ }^{2}$ The Emili Sagol Creative Arts Therapies Research Center, University of Haifa, Haifa, Israel, ${ }^{3}$ School of Theater and \\ Music, University of Illinois at Chicago, Chicago, IL, United States
}

Keywords: emotion recognition, Laban movement analysis, motor, emotion, movement, bodily emotional expressions, dance-movement therapy

\section{A Corrigendum on}

How Do We Recognize Emotion From Movement? Specific Motor Components Contribute to the Recognition of Each Emotion

by Melzer, A., Shafir, T., and Tsachor, R. P. (2019). Front. Psychol. 10:1389. doi: $10.3389 /$ fpsyg.2019.01389

In the original article, there was a mistake in Figure 3 and Figure 4 as published. Figure 3 was mistakenly published attached to the figure legend of Figure 4, while Figure 4 was mistakenly put together with the figure legend for Figure 3. The corrected Figure 3 and Figure $\mathbf{4}$ appear below.

The authors apologize for this error and state that this does not change the scientific conclusions of the article in any way. The original article has been updated.

Copyright $\odot 2020$ Melzer, Shafir and Tsachor. This is an open-access article distributed under the terms of the Creative Commons Attribution License (CC BY). The use, distribution or reproduction in other forums is permitted, provided the original author(s) and the copyright owner(s) are credited and that the original publication in this journal is cited, in accordance with accepted academic practice. No use, distribution or reproduction is permitted which does not comply with these terms. 


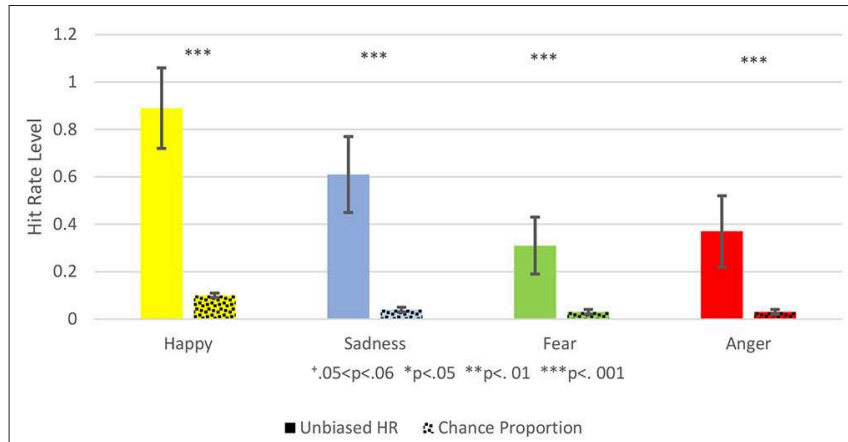

FIGURE 3 | This figure shows the Comparison between the Unbiased Hit Rate and the Chance Proportion, i.e., the hit rate that would have been expected by chance. Unbiased Hit Rate is colored with a full color, and the chance proportion is marked with dots. Each emotion is represented by a different color: Yellow for happiness, blue for sadness, green for fear, red for anger. Hit Rate mean is represented by the bar's height and standard deviation by the black brackets. The Significance level is marked: ${ }^{+} 0.05<p<0.06$,

${ }^{\star} p<0.05,{ }^{* \star} p<0.01,{ }^{\star \star \star} p<0.001$

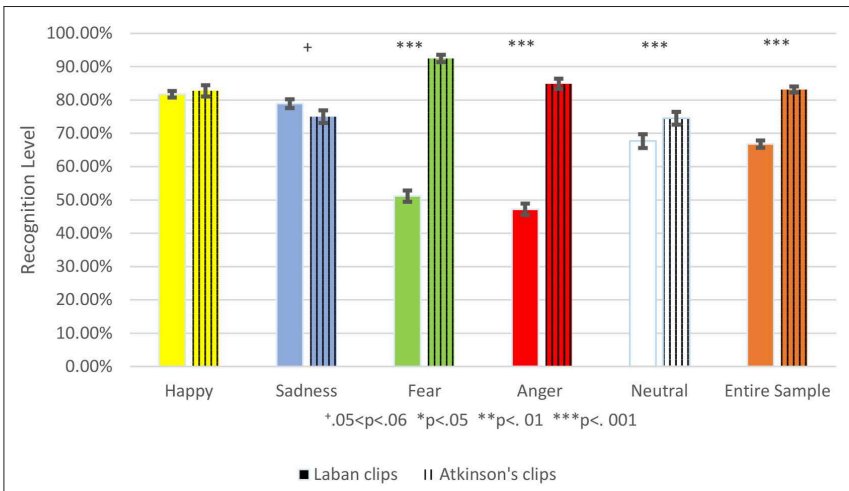

FIGURE 4 | This shows the Comparison between the percent of correct emotion recognition from the Laban stimuli to those from Atkinson's validated clips. The Laban recognition level is colored with a full color, and Atkinsons' validated clips are marked with vertical lines. Each emotion is represented by a different color: Yellow for happiness, blue for sadness, green for fear, red for anger, and white for the neutral emotion. The entire sample is marked orange. Accuracy mean is represented by the bar's height and standard deviation by the black brackets. The significance level is marked: ${ }^{+} 0.05<p<0.06$, ${ }^{\star} p<0.05,{ }^{* *} p<0.01,{ }^{* \star} p<0.001$. 